Review

\title{
Principles of Designing and Implementing Agricultural Extension Programs for Reducing Post-harvest Loss
}

\section{Paul E. McNamara and Joyous S. Tata *}

The Department of Agricultural and Consumer Economics, University of Illinois Urbana Champaign, 326 Mumford Hall, 1301 W. Gregory Drive Urbana, IL 61801, USA; E-Mail: mcnamar1@illinois.edu

* Author to whom correspondence should be addressed; E-Mail: sjtata@illinois.edu; Tel.: +1-217-300-3561; Fax: +1-217-244-7088.

Academic Editor: Sanzidur Rahman

Received: 31 August 2015 / Accepted: 16 October 2015 / Published: 28 October 2015

\begin{abstract}
Post-harvest losses represent a significant threat to food security and farmer incomes worldwide. It is an inefficiency in the global food production system that is avoidable. In deducing principles of designing and implementing agricultural extension programs to reduce post-harvest losses, valuable lessons can be gleaned from the handful of previous extension projects and programs addressing post-harvest loss. Abstracting principles from previous experiences and using this to inform future post-harvest loss prevention programs is an evidence-based approach to arrive at solutions to this problem. This paper reviews extension programs for post-harvest loss prevention, before presenting key principles abstracted from the review that should be taken into consideration for future post-harvest loss prevention programs. This paper aims to contribute to knowledge on the role of agricultural extension in the design of post-harvest loss reduction efforts in developing countries.
\end{abstract}

Keywords: post-harvest loss; agricultural extension; program design; enabling environment; dimensionality; process approach

\section{Introduction}

It is estimated that a third of food produced worldwide is lost and or wasted [1]. Post-harvest loss is an important threat to food security, loss in farmer incomes, and inefficiency in the global food system. The Food and Agricultural Organization (FAO) estimates that the value of post-harvest loss in 
Sub-Saharan Africa is about US\$4 billion a year out of an annual grain crop value of US\$27 billion produced in the years 2005-2007 [2]. Important elements of the post-harvest loss challenge include: multiple points of intervention, multiple value chains, multiple technologies (a dimensionality problem in terms of the technology), and value chains embedded in weak and poorly developed agricultural systems. Post-harvest losses are also due to agricultural systems affected by poor policy choices, as well as institutional capacity constraints, and in some cases, weaknesses in the investment and private sector business-operating climate $[3,4]$.

This multiple cause characteristic of the post-harvest loss problem makes it difficult to deduce general principles to inform post-harvest loss prevention programs. Nevertheless, this paper addresses this challenge because we are convinced that such broad based principles will be beneficial to donors, governments, and the many non-state actors in the agricultural sector. The paper is organized as follows: following the introduction, we review extension programs that have included post-harvest loss prevention as a major objective. This is followed by a discussion of the challenges identified in the reviewed extension programs. The fourth section of the paper articulates broad based principles that should guide post-harvest loss prevention (PHLP) extension programs, deduced from the findings in previous sections of the paper. The paper concludes in section five with a summary of its arguments.

\section{PHLP Extension Experiences in Developing Countries}

Tyler et al. [3] carried out a broad-based assessment of post-harvest loss prevention programs for grains in developing countries, funded by bilateral and multilateral donors. They note that determined global efforts to tackle the problem of post-harvest loss started in the 1970s led by the United Nations through the Post-harvest Food Loss (PFL) Trust Fund Programme implemented by the Food and Agricultural Organization (FAO). Other institutions that took up the challenge then included the World Bank, the European Development Fund, and the International Foundation for Science. A major drawback they observed was that post-harvest loss prevention programs focused on losses at farm level and were studying losses along the crop value chain from production to consumption.

In the Philippines, the Postharvest Horticulture Training and Research Center (PHTRC) has been at the forefront of research and dissemination of knowledge on how to reduce post-harvest losses of horticultural crops [5]. The PHTRC was established in 1977 and is part of the University of the Philippines Los Banos (UPLB) College of Agriculture. Since its creation the PHTRC has received support from similar collaborating institutions in Australia, England, Israel, Japan, and the United States. This has been critical in the PHTRC fulfilling its mission of training experts able to provide solutions to the post-harvest loss problem in the Association of Southeast Asian Nations (ASEAN). To this end the PHTRC has trained personnel from 22 countries on post-harvest loss prevention.

The PHTRC carries out basic research on perishable crops to understand their physiology and biochemistry; the results of their work have contributed to the design of appropriate technology to prevent post-harvest losses of perishable crops in the ASEAN. The PHTRC also develops instructional materials (books, manuals, and visual aids) for the teaching of post-harvest prevention to its students, for public use, and for instruction in foreign countries like Thailand and Indonesia that have invited the PHTRC to train its personnel. Despite the existence of the PHTRC and its educational activities, post-harvest loss prevention education is only carried out in just about 20 of the more than 
200 agricultural colleges in the Philippines. Bautista et al. [5] noted that post-harvest education in Philippines is hampered by loss of trained manpower, slow replacement of manpower, and a widespread belief that techniques used for the post-harvest handling of grains is the same for perishable crops.

The World Vegetable Center (AVRDC) with funding from the Asian Development Bank implemented two post-harvest training and extension projects in Cambodia, Laos, and Vietnam from 2005-2010 [6]. The first phase of the projects, which ran from 2005-2007, focused on reducing post-harvest loss of vegetable crops in the three countries and also included training for their National Agricultural and Research Extension System (NARES) personnel and partners. The projects also involved resource persons drawn from Thailand, Myanmar, China, and the Philippines. The projects developed simple, low cost and appropriate post-harvest technologies for smallholder vegetable farmers. The post-harvest handling techniques and simple technologies that were developed were published in local languages and disseminated through trained extension agents.

The second phase of the project which was from 2009-2010 evaluated the impact of the first phase in terms of adoption of the post-harvest technologies developed. It found that the projects had very strong impacts on rural farmers as adopters experienced $25 \%-30 \%$ higher incomes, and a ten-fold reduction in crop losses from $20 \%-30 \%$ to $2 \%-3 \%$. Acedo Jr. et al. [6] argue that to increase the post-harvest technology adoption rate (highest in Vietnam at 60\% and lowest in Cambodia at 27\%) financial services providers should be included in post-harvest training programs. These are needed to provide credit facilities to smallholder farmers to be able to acquire the low cost post-harvest technologies. Acedo Jr. et al. [6] also call for successful trainees to be used as resource persons in training programs to increase the programs' experiential learning content, and enhance program value and credibility.

Barrett et al. [7] carried out a three-year project funded by the USAID on 'Extension of Appropriate Post-Harvest Technology in Sub-Saharan Africa'. The project had three major objectives. The first was to train 30 persons (researchers, extension agents, development workers) from Rwanda, Ghana, Kenya, Tanzania, Benin and Gabon as post-harvest specialists via E-learning in the first year. The second was to design and establish a 'Postharvest Training and Services Center' (PTSC) in Kigali, Rwanda, in the second year. The third objective was to provide demonstrations, training programs and conduct adaptive research on innovative small-scale appropriate postharvest technologies at the PTSC in collaboration with Trainees and local extension personnel in the second and third year.

At the end of the project, the PTSC successfully trained 36 (17 men, 19 women) post-harvest loss prevention extension agents from seven African countries (Rwanda, Ghana, Kenya, Tanzania, Benin, Ethiopia, and Uganda). The PTSC was now located in Tanzania due to the Rwandan project partner not being able to provide a facility to host the PTSC. The trainees received instructions on Commodity Systems Assessment (CSA), post-harvest systems research (PSR), postharvest demonstration and extension program design, and cost-benefit analysis. Barrett et al. [7] maintain that the 36 post-harvest extension agents have already trained approximately 16,000 smallholder farmers in their various home countries. The PTSC pilot training curriculum is now part of a Global Post-harvest E-learning Program run by the USA-based Postharvest Education Foundation (PEF). 


\section{Challenges to Designing and Implementing PHLP Extension}

When considering efforts to reduce post-harvest loss significantly in the developing countries of SSA and South and Southeast Asia, what dimensions of the phenomenon shape how we think about the challenge of large-scale programs? Especially, what dimensions of the problem are relevant to utilizing insights from extension programs?

Kitinoja et al. [8] asserts that post-harvest science, education and extension services should be integrated into the agricultural curriculum in developing countries. They maintain that this is because there is a very urgent need for capacity building in developing countries with regards to post-harvest policy formulation at the level of government, research, design of appropriate technology, and extension services. They also proposed that post-harvest science and education be taught from grade school through university, and for developing countries to establish a Postharvest Working Group focus on solving post-harvest problems. In addition, Kitinoja et al. [8] call for developing countries to set up 'Postharvest Training and Services Centers' for testing of innovations under local conditions, providing hands-on training, and providing practical information to different actors including women. They also call for regional collaboration on training amongst postharvest groups in the same region.

In addition to getting the institutional and policy environment right, the large variety of crops and the many different post-harvest processes they require means that post-harvest extension is complex. It involves linkages up and down the agricultural supply chain [9], though some experts feel that post-harvest loss challenges are greatest at the "farmer-producer end of the supply chain" [10] (p. 17). In addition, many different actors have decision-making power that affects the level of post-harvest loss in these chains: farmers, processors, importers and suppliers, machine and tractor service providers, millers, distributors and storage businesses, marketing channel actors, input dealers, as well as institutions such as credit markets, labor markets, output markets, and academic and commercial researchers. Figure 1 illustrates this complexity in a typical crop production to consumption value chain, while Figure 2 is a simplified model of how post-harvest losses reduces the volume, quality and consequently the value of crops along the production to consumption value chain.

As illustrated in Figures 1 and 2, compared to many archetypal agricultural innovations such as adoption of a new seed variety or adoption of an innovation in water management like drip irrigation, innovations necessary to reduce post-harvest loss would in many cases involve more nodes in the agricultural supply chain and potentially more actors.

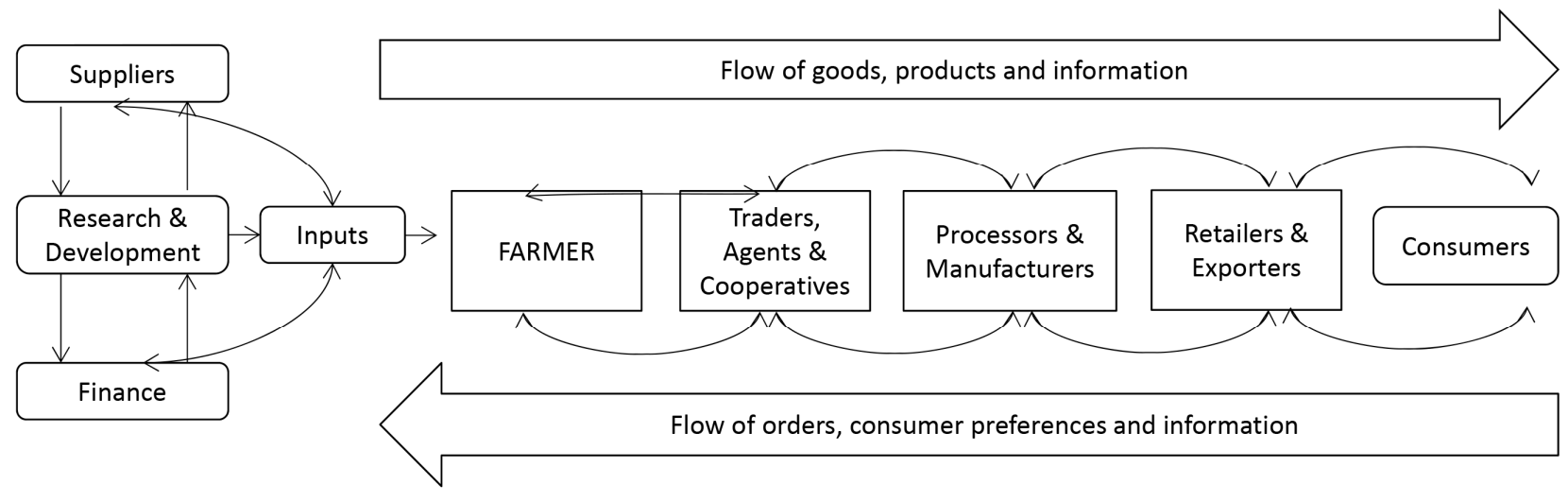

Figure 1. Production to Consumption Value Chain [4]. 


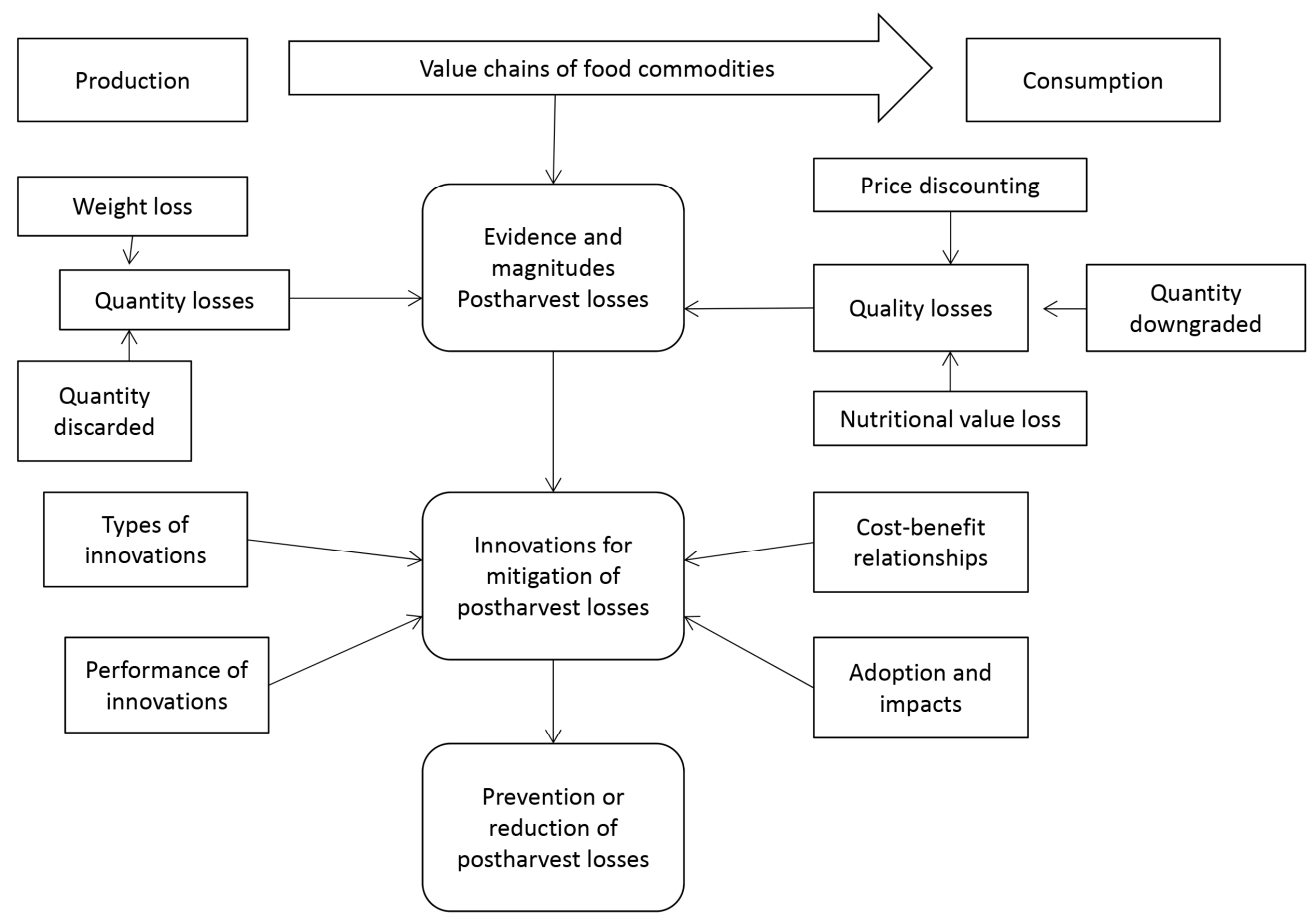

Figure 2. Post-harvest loss along a production to consumption food crop value chain [1].

A further level of complexity or dimensionality of the post-harvest loss prevention challenge is the agricultural investment environment [8]. This determines whether industry actors from farmers to end product distributors will be willing to invest capital and other scarce resources into their operations. On the technical side, multiple approaches and technological products (some low-cost, others not) exist to help reduce post-harvest losses. In developing countries, simple low cost technologies have greater chances of being adopted by smallholder farmers [11]. However, technically sound innovations may fail to become adopted if other aspects of the crop value chain are inhibiting or reducing the ability of adopters to increase net incomes through the technological improvement. In cases where bottlenecks occur at the milling stage, even if post-harvest losses can be prevented on the farm, farmers would hesitate to invest in the loss-reducing technology. Similarly, if a technological advance in post-harvest loss is available but credit is highly constrained, smallholder farmers would not be able to adopt the technology [1].

The post-harvest loss prevention extension challenge displays multiple dimensions, which indicate that a multi-pronged extension approach is needed to reach the various decision-makers and actors involved. Given scarce resources, governments and donors face the challenge of prioritizing where to target their research, education, demonstration, and extension funds for a post-harvest loss prevention program [3].

Extension should be the central and integrating element throughout the supply chain in a program to reduce post-harvest loss [12]. Extension explains the needs of the farmers to actors and agencies and informs the farmer of opportunities available to them. Given the urgency of providing solutions to the post-harvest loss challenge facing farmers in developing countries, and the many innovative post-harvest loss prevention programs now being funded by donors $[1,7,8,11]$, the capacity to design and implement post-harvest loss prevention extension programs should also be accorded very urgent attention. The principles we provide in the next section of this paper is one small step in this direction. 


\section{Principles of Extension Program Design and Implementation Relevant to Addressing the Post-Harvest Loss Challenge}

What principles can inform the design and implementation of agricultural extension programs to reduce post-harvest losses in a developing country? In this section we provide seven principles abstracted from extension programs linked to post-harvest loss prevention.

\subsection{Begin with the Audience in Mind}

How do farmers think about post-harvest losses? Are they already experimenting and seeking out solutions? What are their local approaches and their level of knowledge concerning the phenomenon? What are their trusted sources of technical information? How good is their access to sources of information (persons who have the expertise, as well as information and communication technologies, ICTs, such as Internet, radio, television, mobile-based services)? Is qualitative research available that reflects the audience's point of view? If it does not exist or is too thin or out-of-date, such research should be included in the design stage. In post-harvest loss prevention, this understanding must be gained from the relevant actors up and down the value chain in question, including farmers, millers and processors, distributors, as well as buyers and marketing agents [8,13]. Understanding of the decision-maker's perspective is important before specific technologies and practices are selected and included in a program to improve efficiency in post-harvest processing.

Program developers can utilize this understanding of the audience's perspective to help shape messages, education, and extension efforts that will promote participation in the post-harvest loss prevention program, and bring about changes in behavior or investments [14]. Messages must be framed in ways that match up with the audience's preferred communication methods in terms of mode: internet, face-to-face, peer and social networks for education, commercial and marketing-based communications, print, video, radio, demonstrations and field tests, research papers, reports to influence thought-leaders, level of language and language option (English, national trade and business language, dialects and tribal languages), as well as level of numeracy and technical detail [15]. Graphic design images should be chosen with the audience in mind so that campaigns avoid any images that might create an unintended communication barrier.

Understanding the gender dimensions of practices and behaviors that influence post-harvest loss is also very important [16]. Potential technologies in harvesting may displace women laborers who traditionally harvest by hand for crops, such as rice or maize. Further, some proposed interventions may receive subsidies and other financial support, and men may primarily capture these benefits. Conversely, programs that narrowly focus on women may disenfranchise men and lead to conflict. Gender considerations can force trade-offs between promoting technical efficiency in a value chain through increased levels of commercialization (better and more efficient processing equipment and higher quality storage and processing) and capturing of benefits along gender lines. 


\subsection{Engage Multiple Actors and Institutions at Their Strengths}

As indicated in Figures 1 and 2, post-harvest loss occurs along a value chain that includes farmers, produce buyers and marketers, input dealers, machinery suppliers and service providers, labor contractors and hired laborers, processors, distributors and truckers, extension agents, as well as researchers and knowledge providers such as institutes and universities. Moving to the broader conception of an agricultural innovation system, we also note the roles of information providers like media outlets, television stations, radio stations, and consultants. All of these chain and system actors have a role to play in a program to reduce post-harvest loss in a value chain [2-4,17].

The post-harvest loss prevention extension program developers have to identify chain actors and system participants at critical nodes where interest and support for a program can be expressed. An example might be identifying, encouraging and supporting lead farmers to demonstrate technologies and approaches to peers. Another is to purposefully involve national research programs and strategic academic partners to engage in programs of action-oriented research and demonstrations. It might also involve various media outlets, from government agency staff to radio stations and broadcasting services.

However, since it really is a supply chain and there really is an innovation system needed, utilizing just one or two types of actors or players will likely not produce the intended impacts. Deciding which actors on which to focus program resources and attention additionally becomes an important task, as no program can engage all the possible players and decision-makers easily or efficiently [3]. Participation and ownership of the process by value chain actors, especially farmers, will create more lasting impacts and engagements [18]; this includes control and voice so that they can act, provide input and feedback into the process of reducing post-harvest losses. Participation will also involve inclusion and input into steering committees and evaluations, as well as involvement in the main activities of the program by serving as peer trainers, educators, commercial partners, and media nodes. By recognizing the variety of chain and system actors and by inviting significant input and participation from the actors, a program is more likely to have lasting deep impact.

\subsection{Finance in a Manner that Corresponds to the Program Goals}

The way large development programs get financed shapes the outcomes and consequences from the programs [3,19]. As part of health sector reforms in Kenya, conditional grants financing from donors and the central government to local counties have been used to incentivize more efficient delivery of public health services [20]. Education reforms, which have included bonus pay for improved teacher performance, have been shown to be an effective incentive mechanism for teachers in developed and developing countries [21].

Given this ability for financing to shape impacts, taking the program goals and mapping the financing directly onto these goals would result in a framework that links payments to the agency or person achieving the results. This is a very important element of smart development program design. Care must be taken so that the way a program is financed, especially the structure and timing of payments, creates incentives and motivation for actors and partners to achieve program outcomes and impacts [2,17]. The source of financing, whether public, private or a public-private partnership also has an impact on 
program outcomes [22,23]. Figure 3 shows the results when different funding sources are combined with different delivery mechanisms.

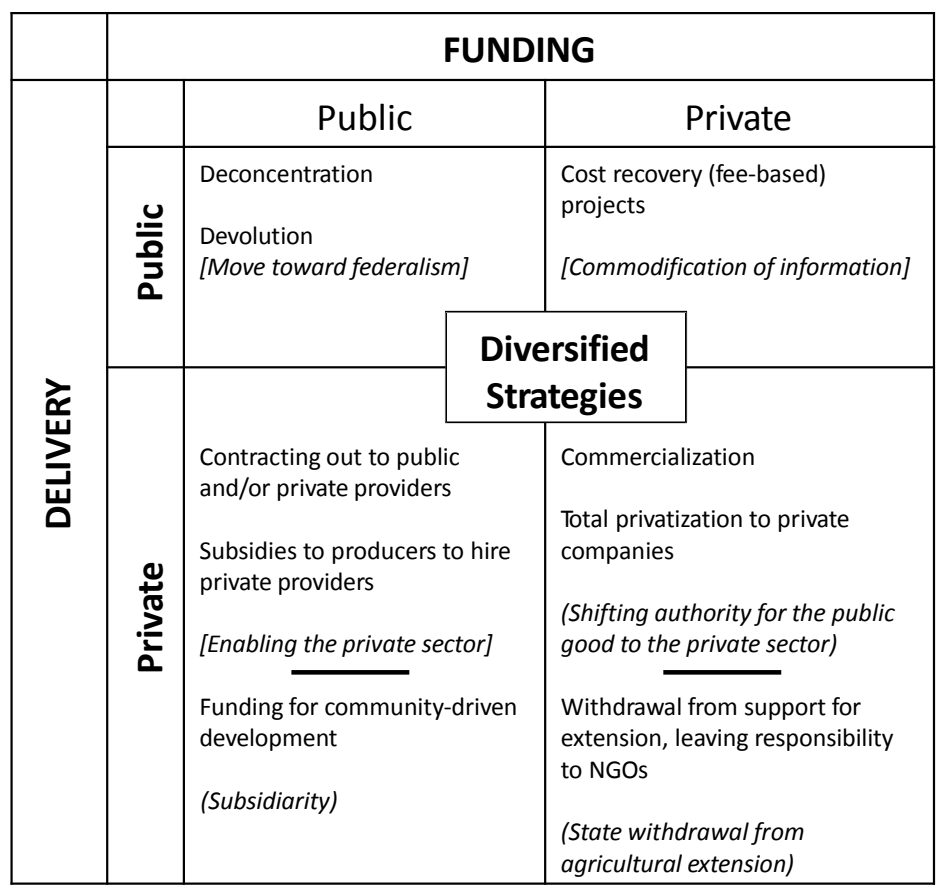

Figure 3. Influence of program financing on operational strategy [24].

\subsection{Manage for Impact}

To achieve significant impacts, extension project management has to encourage and incentivize the performance of the extension system [2]. Specific actions and management tools, such as the monitoring and evaluation system and the reporting systems, need to align with the mission of the program in strengthening the system. One dimension of managing for impact is discerning what various partners can contribute to the overall effort and providing them with sufficient resources to achieve results. Holding them accountable via monitoring and reporting structures, and having sanctions if the actions are poorly performed or are not of a sufficient quantity is important [23]. In systems and supply chains where key partners like farmer organizations or public sector extension are weak, this aspect of management becomes quite challenging. NGOs and private sector entities can be engaged but oftentimes the impacts may not be sustainable.

\subsection{Employ Multiple Modes and Methods of Communication}

Effective extension programs often employ multiple modes of communication [15]. A national program on soil fertility might utilize demonstrations through farmer field schools, as well as radio messages, fact sheets, training sessions for extension agents and lead farmers, videos, print media and newspaper articles. Utilizing multiple modes of communication makes sense because the agricultural systems have multiple actors and multiple types of decision-makers. Given variations in education levels and preferred communication modes, it is pertinent to use a variety of communication approaches within a program in order to increase effectiveness [25]. 
A variety of approaches in extension communications is also necessary because learning styles and readiness for behavior change among people are varied [15]. Consider rice millers in a developing country: mills are operated by agricultural business associations, farm groups, and private businesses. While some decision-makers may realize their equipment process rice inefficiently with significant broken rice, leading to a lower quality rice than could be achieved with improved equipment, others may not realize there could be an issue here at all. Therefore, millers may vary regarding their perception of a need to invest in new equipment. Having a variety of media channels and approaches would help reach rice millers wherever they find themselves in terms of perception of the need for change.

A last reason for multiple modes of communication concerns the economics of messaging. Given the challenge of formulating effective extension messages, with technical and communication credibility, using multiple modes of communication ensures that the good message reaches the largest number clients. Another dimension of the economies of scale in messaging concerns using the network of a program. Good extension programs utilize their internal networks to move messages via multiple modes [15]. These coordination networks for field extension activities can be effectively utilized to distribute and disseminate videos, audio for radio, articles to local media, as well as lesson and activity plans for field activities, and to deliver trainings for farmers and farmer groups.

\subsection{Embrace the Tension between the Technology Diffusion and Process Approaches}

There is a tension that exists within extension program design: approaches that emphasize the "technology" or a specific product or innovation versus the process or system oriented approach. In the technology approach, the extension agent is the expert; in the system approach, farmers are owners of a learning and discovery process with power and agency to investigate and select approaches that will improve their lives. In the technology approach, the emphasis is transfer of knowledge about a technology, while the system approach builds social capital and capacity of farmers. The system approach enables farmers adopt a specific technology if they so choose, and builds their capacity to link with suppliers of technology and information as well as with market opportunities for their crops $[2,26]$.

Program designers for a post-harvest loss prevention program must possess an awareness of these design issues and how they may impact program sustainability, effectiveness, costs, and staffing. Further, many variants of these polar approaches exist and good elements can be integrated into a hybrid program. A related question is, how does the program develop the capacity of supply chain and innovation system actors, from farmers and further along the chain, to build their own capacity and that of their organizations to independently assess and acquire technologies and approaches to improve their post-harvest efficiency?

\subsection{Realize the Enabling Environment can Swamp the Program's Good Work}

Another lesson from extension practice and program design for post-harvest loss prevention program designers is that the overall agricultural and investment policy environment is critically important [2,22]. Agricultural development projects, and small business and enterprise development projects, in developing countries, work in the context of an overall policy environment that is uncertain and sometimes contradictory. In conditions where high budget deficits lead to high interest rates (cost 
of capital) and weak exchange rates, export producers may experience increased demand, but unstable exchange rates could lead to higher cost of imported goods including agricultural inputs like fertilizers and new equipment. Thus a policy that would lead to growth in exports could also dampen investment in the agricultural sector with consequent impact on post-harvest loss.

Investment climate considerations also play an important role in mobilizing the private sector investments necessary to move a major post-harvest loss prevention effort forward [22]. This includes security of contracts, trade agreements (including phytosanitary regulations), food industry infrastructure, procedures and ability of government to participate in public/private partnerships, land title, and access to credit [4]. Program designers must understand that the macro-level environment can determine the success of programs that are fully endorsed by the national government.

This underscores the importance of macro-level variables in any scoping exercise at the country level. It may be necessary to design post-harvest loss prevention programs to work with other large-scale agricultural initiatives, such as World Bank-funded agricultural productivity improvement projects, USAID and other donor-funded agricultural development projects, so as to work under an enabling agricultural sector environment [13,27].

\section{Conclusions}

Extension programs that achieve significant impacts in terms of behavior and practice changes, as well as agricultural productivity increases, succeed as a result of good program designs and effective implementation management. They succeed because they provide a platform and avenue for desired change with their participants and because the program elements that support this change at the household, farm, firm or community level are present and vibrant. Making this happen is challenging in many environments because it involves mobilizing multiple actors, significant institutional capacity and human resources, as well as a sound suite of technical or practical innovations. By considering the experiences of previous post-harvest loss prevention programs and agricultural extension programs more broadly, post-harvest loss prevention program designers will increase their likelihood for significant program impacts.

In this regard, this paper has presented seven design principles which we consider to be fundamental to good extension program design, these include: begin with the audience in mind; engage multiple actors and institutions at their strengths; finance in a manner that corresponds to the program goals; manage for impact; employ multiple modes and methods of communication; embrace the tension between the technology diffusion and process approaches; and lastly realize the enabling environment can swamp the program's good work. We do not maintain that these seven principles are a silver-bullet guaranteeing sure success in extension program design, but we do assert that they are foundational and where extension program designers ignore any of these, they risk program failure attributable to weak program design.

\section{Acknowledgements}

This work was supported by the United States Agency for International Development (USAID) (grant No. AID-OAA-L-10-00003) through the Modernizing Extension and Advisory Services (MEAS) program at the University of Illinois Urbana Champaign, USA. The material is based on work submitted 
to the Global Learning Assessment project conducted by the ADM Institute for the Prevention of Post-harvest Loss and financially supported by the Rockefeller Foundation. The authors wish to thank Andrea Bohn and Emmanuel Nuesiri for reviewing earlier draft of the paper. We also wish to thank Kathryn Heinz, Alyssa Brodsky and Cortney Eisenmann for manuscript preparation.

\section{Author Contributions}

Paul E. McNamara and Joyous S. Tata conceived the outline and wrote the paper.

\section{Conflict of Interests}

The authors declare no conflict of interest.

\section{References}

1. Affognon, H.; Mutungi, C.; Sanginga, P.; Borgemeister, C. Unpacking postharvest losses in Sub-Saharan Africa: A meta-analysis. World Dev. 2015, 66, 49-68.

2. World Bank. Missing Food: the Case of Postharvest Grain Losses in Sub-Saharan Africa; 60371-AFR; World Bank: Washington, DC, USA, 2011.

3. Tyler, P.S.; Boxall, R.A. Post Harvest Loss Reduction Programmes: A Decade of Activities —What Consequences? Trop. Stored Prod. Inf. 1984, 50, 4-13.

4. Hodges R.J.; Buzby, J.C.; Bennett, B. Postharvest losses and waste in developed and less developed countries: Opportunities to improve resource use. J. Agric. Sci. 2011, 149, 37-45.

5. Bautista, O.K.; Esguerra, E.B. Postharvest research, education and training in the Philippines: the role of the postharvest horticulture training and research center from the past to the future. Acta Hortic. 2012, 943, 41-46.

6. Acedo Jr. A.; Weinberger, K.; Holmer, R.J.; d'Arros Hughes, J. Postharvest research, education and extension: AVRDC-The World Vegetable Center's experience. Acta Hortic. 2012, 943, 47-61.

7. Barrett, D.; Kitinoja, L.; Chen, J.; Nenguwo, N. Pilot project final report: Extension of appropriate postharvest technology in sub-Saharan Africa: a postharvest training and services center; USAID Horticultural Innovation Lab: Davis, CA, USA, 2014.

8. Kitinoja L.; Saran S.; Roy, S.K.; Kader, A.A. Postharvest technology for developing countries: Challenges and opportunities in research, outreach and advocacy. J. Sci. Food Agric. 2011, 4, 597-603

9. Dubey, S.K.; Sah, U.; Singh, A.K.; Linkage Perspective in Agricultural Extension; Daya Publishing House: New Delhi, India, 2011.

10. Institution of Mechanical Engineers. Global food: Waste not, Want not; Institution of Mechanical Engineers: London, UK, 2013; pp. 17-24.

11. Kitinoja, L. Innovative small-scale postharvest technologies for reducing losses in horticultural crops. Ethiop. J. Appl. Sci. Technol. 2013, 1, 9-15.

12. Bauer, E.; Hoffmann, V.; Keller, P. Principles and guidelines for extension projects. In Rural extension Examples and Background Material, 3rd ed.; Hoffmann, V., Christinck, A., Lemma, M., Eds.; Margraf Publishers: Weikersheim, Germany, 2009; Volume 8, pp. 406-409. 
13. Costa, S.J. Reducing Food Losses in Sub-Saharan Africa: An 'Action Research' Evaluation Trial from Uganda and Burkina Faso; UN World Food Programme: Kampala, Uganda, 2014.

14. Jakku, E.; Thorburn, P.J. A conceptual framework for guiding the participatory development of agricultural decision support systems. Agri. Syst. 2010, 103, 675-682.

15. Leeuwis, C.; Van den Ban, A. Communication for Rural Innovation: Rethinking Agricultural Extension; Blackwell Publisher: Hoboken, New Jersey, NJ, USA, 2004.

16. Peterman, A.; Behrman, J.; Quisumbing, A. A Review of Empirical Evidence on Gender Differences in Nonland Agricultural Inputs, Technology, and Services in Developing Countries; IFPRI Discussion Paper 00975; International Food Policy Research Institute (IFPRI): Washington, DC, USA, 2010.

17. Swanson, B.E. Global Review of Good Agricultural Extension and Advisory Service Practices; Food and Agricultural Organization: Rome, Italy, 2008.

18. Scarborough, V.; Killough, S.; Johnson, D.A.; Farrington, J. Farmer-Led Extension: Concepts and Practices, Intermediate Technology Publications Ltd.: London, England, 1997.

19. Belt, J.; Heemskerk, W. The Business of Agricultural Business Services: Working with Smallholders in Africa; Wongtschowski, M., Belt, J., Heemskerk, M., Kahan, D., Eds.; Royal Tropical Institute: Amsterdam, the Netherlands, 2013.

20. Chen, A.; Mulaki, A.; Williamson, T. Incentivizing Performance: Conditional Grants in Kenya'S Health System; Futures Group: Health Policy Project, Washington, DC, USA, 2014.

21. Vegas, E.; Ganimian, A. Theory and Evidence on Teacher Policies in Developed and Developing Countries; Inter-American Development Bank: Washington, DC, USA, 2013.

22. Anderson, J.R.; Feder, G. Agricultural extension: Good intentions and hard realities. World Bank Res. Obs. 2004, 19, 41-60.

23. Poulton, C.; Macartney, J. Can public-private partnerships leverage private investment in agricultural value chains in Africa? A preliminary review. World Dev. 2012, 40, 96-109.

24. Rivera, W.M.; Qamar, M.K. Agric. Extension, Rural Dev. Food Security Challenge. Publishing Management FAO: Viale delle Terme di Caracalla, Rome, Italy, 2003.

25. Age, A.I.; Obinne, C.P.O.; Demenongu, T.S. Communication for sustainable rural and agricultural development in Benue State. Niger. Sustain. Agric. Res. 2012, 1, 118-129.

26. Pagon, J. Footprints for the future through local area planning. In APEN International Conference, Victoria, Australia, 6-8 March 2006.

27. Hewett E.W. Postharvest technology innovation and opportunities of extension for horticultural produce: Perspective and trends. Acta Hortic. 2012, 943, 25-32.

(C) 2015 by the authors; licensee MDPI, Basel, Switzerland. This article is an open access article distributed under the terms and conditions of the Creative Commons Attribution license (http://creativecommons.org/licenses/by/4.0/). 